\title{
Loss of conserved ubiquitylation sites in conserved proteins during human evolution
}

\author{
DONGBIN PARK, CHUL JUN GOH, HYEIN KIM, JI SEOK LEE and YOONSOO HAHN
}

Department of Life Science, Chung-Ang University, Seoul 06974, Republic of Korea

Received January 30, 2018; Accepted July 6, 2018

DOI: $10.3892 / \mathrm{ijmm} .2018 .3772$

\begin{abstract}
Ubiquitylation of lysine residues in proteins serves a pivotal role in the efficient removal of misfolded or unused proteins and in the control of various regulatory pathways by monitoring protein activity that may lead to protein degradation. The loss of ubiquitylated lysines may affect the ubiquitin-mediated regulatory network and result in the emergence of novel phenotypes. The present study analyzed mouse ubiquitylation data and orthologous proteins from 62 mammals to identify 193 conserved ubiquitylation sites from 169 proteins that were lost in the Euarchonta lineage leading to humans. A total of 8 proteins, including betaine homocysteine S-methyltransferase, clin and CBS domain divalent metal cation transport mediator 3 , ribosome-binding protein 1 and solute carrier family 37 member 4 , lost 1 conserved lysine residue, which was ubiquitylated in the mouse ortholog, following the human-chimpanzee divergence. A total of 17 of the lost ubiquitylated lysines are also known to be modified by acetylation and/or succinylation in mice. In 8 cases, a novel lysine evolved at positions flanking the lost conserved lysine residues, potentially as a method of compensation. We hypothesize that the loss of ubiquitylation sites during evolution may lead to the development of advantageous phenotypes, which are then fixed by selection. The ancestral ubiquitylation sites identified in the present study may be a useful resource for investigating the association between loss of ubiquitylation sites and the emergence of novel phenotypes during evolution towards modern humans.
\end{abstract}

Correspondence to: Professor Yoonsoo Hahn, Department of Life Science, Chung-Ang University, 84 Heukseok-ro, Dongjak-gu, Seoul 06974, Republic of Korea

E-mail: hahny@cau.ac.kr

Abbreviations: aa, amino acid; ER, endoplasmic reticulum; $\mathrm{mUbiSiDa,}$ mammalian ubiquitination site database; PTM, post-translational modification; SNP, single nucleotide polymorphism; UPR, unfolded protein response

Key words: ubiquitylation, evolution, human, post-translational modification, loss

\section{Introduction}

Ubiquitylation, in which the highly conserved 76-residue polypeptide ubiquitin is covalently attached to a lysine residue of substrate proteins, mediates the targeted destruction of ubiquitylated proteins by the ubiquitin-proteasome system (1-4). The ubiquitin-mediated protein degradation pathway serves a crucial role in the efficient and specific removal of misfolded proteins and certain key regulatory proteins $(5,6)$. Ubiquitin and other ubiquitin-like proteins, including autophagy-related protein 8, Ubiquitin-like protein ISG15, NEDD8 conjugating enzyme UBE2F and SUMO-conjugating enzyme UBC9, may all be targeted to the same lysine residue, and in this way they are involved in regulating a number of cellular processes including transcription, the cell cycle and signal transduction pathways $(1,3,7,8)$. Modified lysine residues, covalently attached not only to ubiquitin but also to other ubiquitin-like proteins, may be identified by high-throughput techniques $(9,10)$. In the present study, the term 'ubiquitylation' is used to refer to ubiquitin and other ubiquitin-like protein modifications.

The lysine residues that are targeted for ubiquitylation may also be modified by acetylation, and so cross-talk between ubiquitylation and acetylation may control the stability of target proteins (11). It is also known that the cross-talk between ubiquitylation and phosphorylation may modulate various regulatory networks (12). For example, ubiquitylation may positively or negatively regulate various protein kinases, either with or without their subsequent degradation (12-14).

A large number of genetic changes have accumulated during human evolution and are responsible for the acquisition of different human phenotypes $(15,16)$. These genetic modifications include the de novo generation of genes (17), emergence of novel transcript isoforms (18) and loss of gene function (19-21). The gain of novel phosphorylation sites in proteins may result in the reorganization of the regulatory circuits $(22,23)$. The gain of lysine residues that are subject to ubiquitylation during human evolution may alter the timing of protein degradation, subcellular localization and the activity of the target proteins (24). Similarly, the gain or loss of $\mathrm{N}$-glycosylation modification sites in conserved proteins may have an effect on protein folding and trafficking, and on adhesion and cell signaling $(25,26)$.

In the present study, we hypothesized that the loss of conserved ubiquitylation sites in highly conserved proteins during evolution may modify the ubiquitin-mediated regulatory network, which 
potentially results in the acquisition of novel phenotypes. Mouse ubiquitylation data compiled in the Mammalian Ubiquitination Site Database (mUbiSiDa) (27) and multiple sequence alignments of orthologous proteins from 62 mammalian species were analyzed to identify the lost conserved ubiquitylation sites in the Euarchonta lineage leading to humans. The timepoint during evolution when the ancestral ubiquitylated lysine residues may have disappeared was then determined.

\section{Materials and methods}

Mouse ubiquitylation site data. The mouse ubiquitylation site data were obtained from the mUbiSiDa database (http://reprod. njmu.edu.cn/mUbiSiDa) to create a non-human ubiquitylation site dataset (27). The database file 'data_2013_10_22.txt' was parsed to extract the mouse ubiquitylation data entries; in total, there were 5,168 entries for mouse proteins (Fig. 1). Each entry contained one or more ubiquitylation sites from a protein isoform sequence, which made the dataset highly redundant. Unique ubiquitylation sites were obtained by comparing 13-amino acid (aa)-long peptide sequences with the ubiquitylation site at the center. Consequently, 17,303 non-redundant ubiquitylation sites were identified from 4,531 mouse proteins.

Mammalian orthologous proteins. Multiple sequence alignments of mammalian proteins, including from humans, were obtained from the University of California Santa Cruz Genome Browser Database (http://genome.ucsc.edu) (28). The 'CDS FASTA alignment from multiple alignment' data of the human hg38 genome track were downloaded using the Table Browser tool. These alignment datasets were derived from the 'multiz100way' alignments (http://hgdownload.cse. ucsc.edu/goldenPath/hg38/multiz100way) (29), and included 62 mammalian species: Humans (Homo sapiens) and 12 other Euarchonta [chimpanzees (Pan troglodytes), gorillas (Gorilla gorilla gorilla), orangutans (Pongo pygmaeus abelii), gibbons (Nomascus leucogenys), rhesus macaques (Macaca mulatta), crab-eating macaques (Macaca fascicularis), baboons (Papio hamadryas), green monkeys (Chlorocebus sabaeus), marmosets (Callithrix jacchus), squirrel monkeys (Saimiri boliviensis), bush babies (Otolemur garnettii) and Chinese treeshrews (Tupaia chinensis)], 13 Glires [squirrels (Spermophilus tridecemlineatus), lesser Egyptian jerboas (Jaculus jaculus), prairie voles (Microtus ochrogaster), Chinese hamsters (Cricetulus griseus), golden hamsters (Mesocricetus auratus), mice (Mus musculus), rats (Rattus norvegicus), naked mole-rats (Heterocephalus glaber), guinea pigs (Cavia porcellus), chinchillas (Chinchilla lanigera), brush-tailed rats (Octodon degus), rabbits (Oryctolagus cuniculus) and pikas (Ochotona princeps)], 25 Laurasiatheria [pigs (Sus scrofa), alpacas (Vicugna pacos), Bactrian camels (Camelus ferus), dolphins (Tursiops truncatus), killer whales (Orcinus orca), Tibetan antelopes (Pantholops hodgsonii), cows (Bos taurus), sheep (Ovis aries), domestic goats (Capra hircus), horses (Equus caballus), white rhinoceroses (Ceratotherium simum), cats (Felis catus), dogs (Canis lupus familiaris), ferrets (Mustela putorius furo), pandas (Ailuropoda melanoleuca), Pacific walruses (Odobenus rosmarus divergens), Weddell seals (Leptonychotes weddellii), black flying-foxes (Pteropus alecto), megabats (Pteropus vampyrus), David's myotis bats
(Myotis davidii), microbats (Myotis lucifugus), big brown bats (Eptesicus fuscus), hedgehogs (Erinaceus europaeus), shrews (Sorex araneus) and star-nosed moles (Condylura cristata)], 6 Afrotheria [elephants (Loxodonta africana), cape elephant shrews (Elephantulus edwardii), manatees (Trichechus manatus latirostris), cape golden moles (Chrysochloris asiatica), tenrecs (Echinops telfairi) and aardvarks (Orycteropus afer afer)], 1 Xenarthra [armadillos (Dasypus novemcinctus)], 3 Marsupialia [opossums (Monodelphis domestica), Tasmanian devils (Sarcophilus harrisii) and wallabies (Macropus eugenii)], and 1 Monotremata [platypuses (Ornithorhynchus anatinus)]. Consequently, a total of 40,424 sequence alignments were downloaded.

Identification of lost ubiquitylation sites and timing of loss. The 13-aa sequences of the 17,303 unique mouse ubiquitylation sites obtained from the mUbiSiDa database were mapped to the mouse sequences within the 40,424 mammalian protein sequence alignments; 15,354 sites were identified in 4,027 proteins. Each position that aligned with a mouse ubiquitylation site was examined using a series of custom scripts in Perl programming language (version 5.22.1) (https://www.perl.org/). Firstly, sites where the human protein contained a non-lysine residue were collected, as it indicated that the modifiable lysine residue was lost in the lineage leading to humans. Following this, putative ancestral ubiquitylation sites where $\geq 70 \%$ of Glires and non-Euarchontoglires species contained a lysine residue were obtained; this condition allowed independent losses in up to $30 \%$ of Glires or non-Euarchontoglires species. As a result, a total of 193 sites from 169 proteins were identified to be lost in the Euarchonta lineage leading to humans following its divergence from the Glires lineage. The timing of the loss of the ubiquitylated lysine residue was determined by examining the multiple sequence alignment and the phylogenetic tree of the mammals included in the present study.

Examination of human single nucleotide polymorphisms. The dbSNP data (build 150) track available in the UCSC Genome Browser was examined to identify potential polymorphisms at the lost ubiquitylation sites of human proteins. Allele frequency information was obtained from dbSNP (https://www.ncbi.nlm. nih.gov/snp) and Exome Aggregation Consortium (ExAC; http://exac.broadinstitute.org) databases.

Examination of multiple modification sites. Lysine residues may be mutually exclusively modified by multiple post-translational modifications (PTMs), including ubiquitylation, ubiquitin-like protein modification, acetylation, and succinylation. To examine whether the mouse ubiquitylation sites may be modified by other PTMs, UniProt database (https://www.uniprot.org) records of mouse proteins were analyzed. When a ubiquitylation site is associated with the term 'MOD_RES' in the feature table, it was considered that the site may be also modified by other PTMs.

\section{Results and Discussion}

Identification of ancestral ubiquitylation sites that are lost in the Euarchonta lineage leading to humans. It was identified that 193 ancestral ubiquitylation sites were lost in 


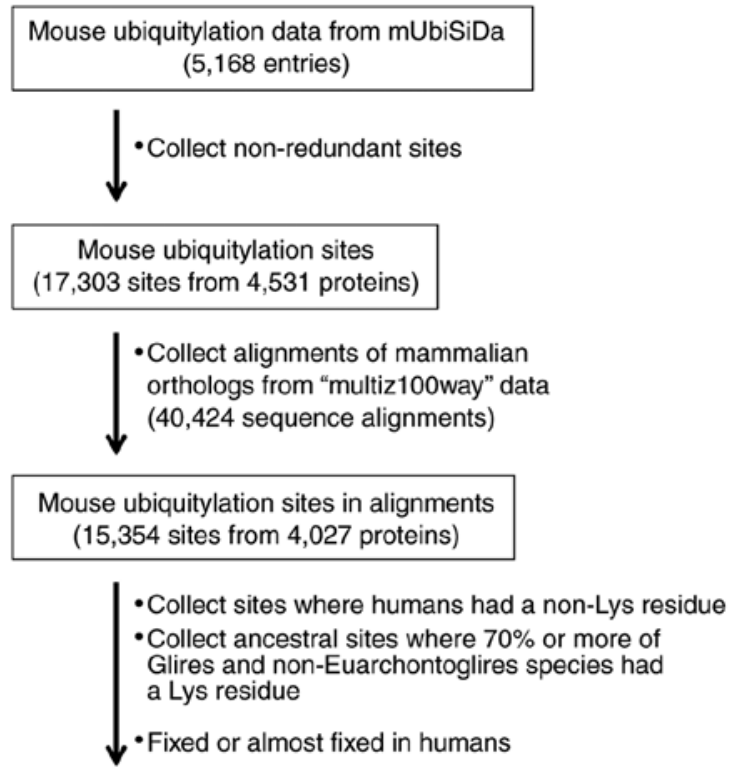

Ubiquitylation sites lost during human evolution (193 sites from 169 proteins)

$\downarrow$

Figure 1. Schematic of the procedure used for the identification of the lost ancestral ubiquitylated lysines during human evolution. A bioinformatics procedure was designed and employed to identify the lost ancestral ubiquitylation sites in the Euarchonta lineage leading to humans. A total of 193 sites from 169 proteins were identified as being lost in the human lineage during evolution. Lys, lysine.

169 human proteins since the Euarchonta lineage diverged from the Glires lineage. A total of 19 proteins lost $>1$ putative ancestral ubiquitylation sites: The protein Titin, which is the largest known protein, lost 5 sites; 2 proteins [achaete-scute homolog 1 and ribosome-binding protein 1 (RRBP1)] lost 3 sites each; 16 proteins [acetyl-CoA acetyltransferase, mitochondrial, cytoplasmic aconitate hydratase, long-chain-fatty-acid-CoA ligase 5, cytosolic 10-formyltetrahydrofolate dehydrogenase, bifunctional purine biosynthesis protein PURH, complement component 3, carbonic anhydrase 3, clustered mitochondria protein homolog, dimethylaniline monooxygenase (N-oxide-forming) 1, nebulin, PDZ domain containing 1 (PDZK1), short-chain dehydrogenase/reductase family 42E member 1 (SDR42E1), protein SEC13 homolog, solute carrier family 12 member 1 , multidrug and toxin extrusion protein 1, and urocanate hydratase] lost 2 sites each; and the remaining 151 proteins lost 1 site each.

The number of conserved ubiquitylation sites that were lost in each branch is demonstrated in Fig. 2, and were as follows: Humans, 8; Hominini (humans and chimpanzees), 3; African great apes, 16; great apes, 6; apes, 15; catarrhines, 33; simians, 75; primates, 26; and Euarchonta, 11. Of the 193 sites that were lost in the lineage leading to humans, 9 events occurred in human proteins following the human-chimpanzee divergence.
A total of 2 human-specific lost ubiquitylation sites are polymorphic in humans. Each of the 8 proteins [betaine homocysteine S-methyltransferase (BHMT), cyclin and CBS domain divalent metal cation transport mediator 3 (CNNM3), epoxide hydrolase 2 (EPHX2), hydroxy- $\delta$-5-steroid dehydrogenase, $3 \beta$ - and steroid $\delta$-isomerase 7 (HSD3B7), PDZK1, RRBP1, SDR42E1, and solute carrier family 37 member 4 (SLC37A4)] that lost 1 conserved ubiquitylated lysine residue following the human-chimpanzee divergence are summarized in Table I. Examination of the human variant data in dbSNP and ExAC databases indicated that the loss of the ubiquitylated lysine was fixed in 6 of these 8 proteins; the 6 proteins were BHMT, CNNM3, EPHX2, HSD3B7, SDR42E1, and SLC37A4.

For 2 of these proteins, PDZK1 and RRBP1, the amino acid position where the ubiquitylated lysine was lost indicated a polymorphism. In the case of PDZK1, the lost ubiquitylation site (amino acid position 171) was polymorphic (dbSNP accession number rs138296787): The ancestral allele (AAA codon for lysine) and the derived allele (AGA codon for arginine) were identified. The frequencies of the 2 alleles demonstrated that the human-specific derived allele forms the majority $(96.70 \%)$ and this allele is, therefore, almost fixed in modern humans. Notably, the derived $G$ allele demonstrated slight differences in frequency distribution across the human populations, with the lowest frequency in Africans (92.63\%) and the highest in South Asians (99.04\%). It is not known whether the difference in frequency of the derived allele is associated with the adaptation of human populations to local environments.

Similarly, for the RRBP1 protein, position 936 also indicated a polymorphism at the ubiquitylation site (rs2229887): The derived allele (AGA codon for arginine) is the major allele with a frequency of $99.70 \%$ compared to the ancestral allele (AAA codon for lysine) and is, therefore, almost fixed in modern humans. The frequency of the derived $\mathrm{G}$ allele was lowest in Africans (97.01\%), while it was 99.81-100.00\% in other populations.

Therefore, human-specific losses of ubiquitylation sites are fixed or almost fixed in modern humans. Presently, to the best of our knowledge, there are no studies describing the phenotypes associated with these polymorphisms in PDZK1 or RRBP1.

Representative cases of human-specific loss of a ubiquitylation site. Among the 8 cases in which a conserved ubiquitylated lysine was lost in humans following the human-chimpanzee divergence, 4 representative cases are demonstrated in Fig. 3. These are BHMT, CNNM3, RRBP1 and SLC37A4.

The human BHMT protein (NCBI accession number NP_001704.2) lost a conserved lysine at aa position 98 (case no. 34) subsequent to the human-chimpanzee divergence (Fig. 3A). Of the 62 mammalian species analyzed in the present study, the lysine residue that was demonstrated to be ubiquitylated in mice was identified to be conserved in 60 species. A high level of sequence conservation of the lysine residue and surrounding region suggests that the ubiquitylation modification may be shared by other mammals. Humans exhibit a glutamic acid residue at this position. Wallabies (M. eugenii), members of the Marsupial family, have a glycine residue, implying that they lost the lysine independently. Notably, the same lysine residue was identified to be succinylated 


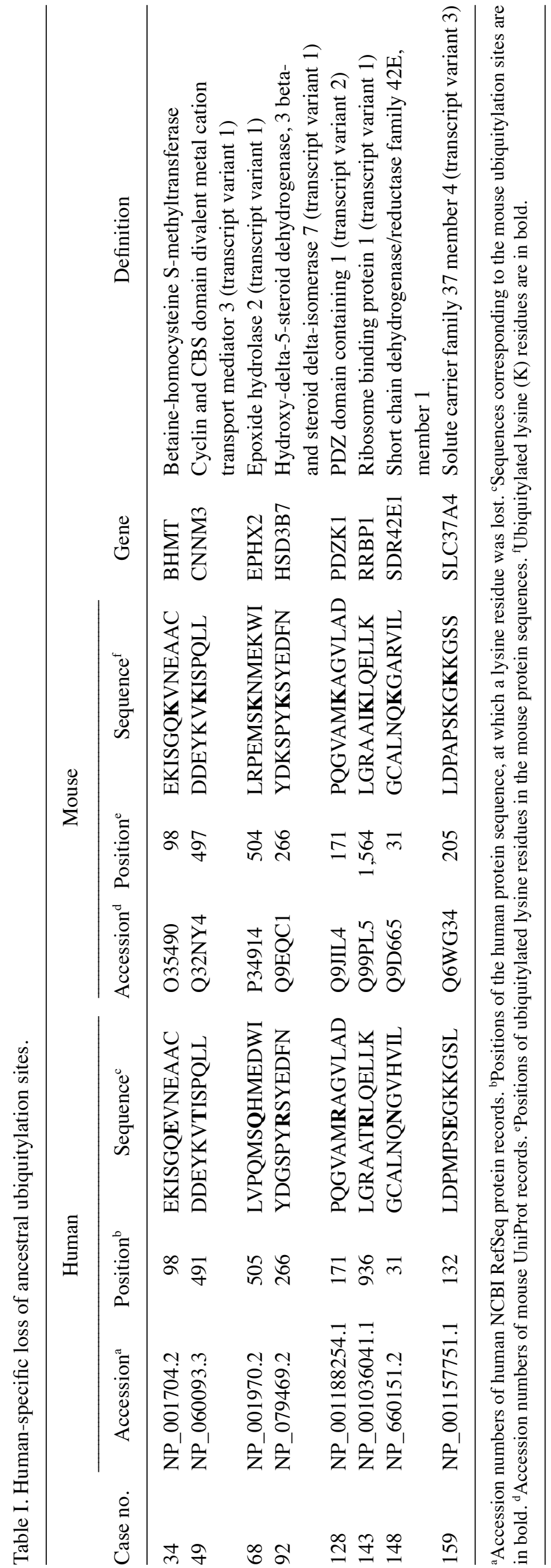




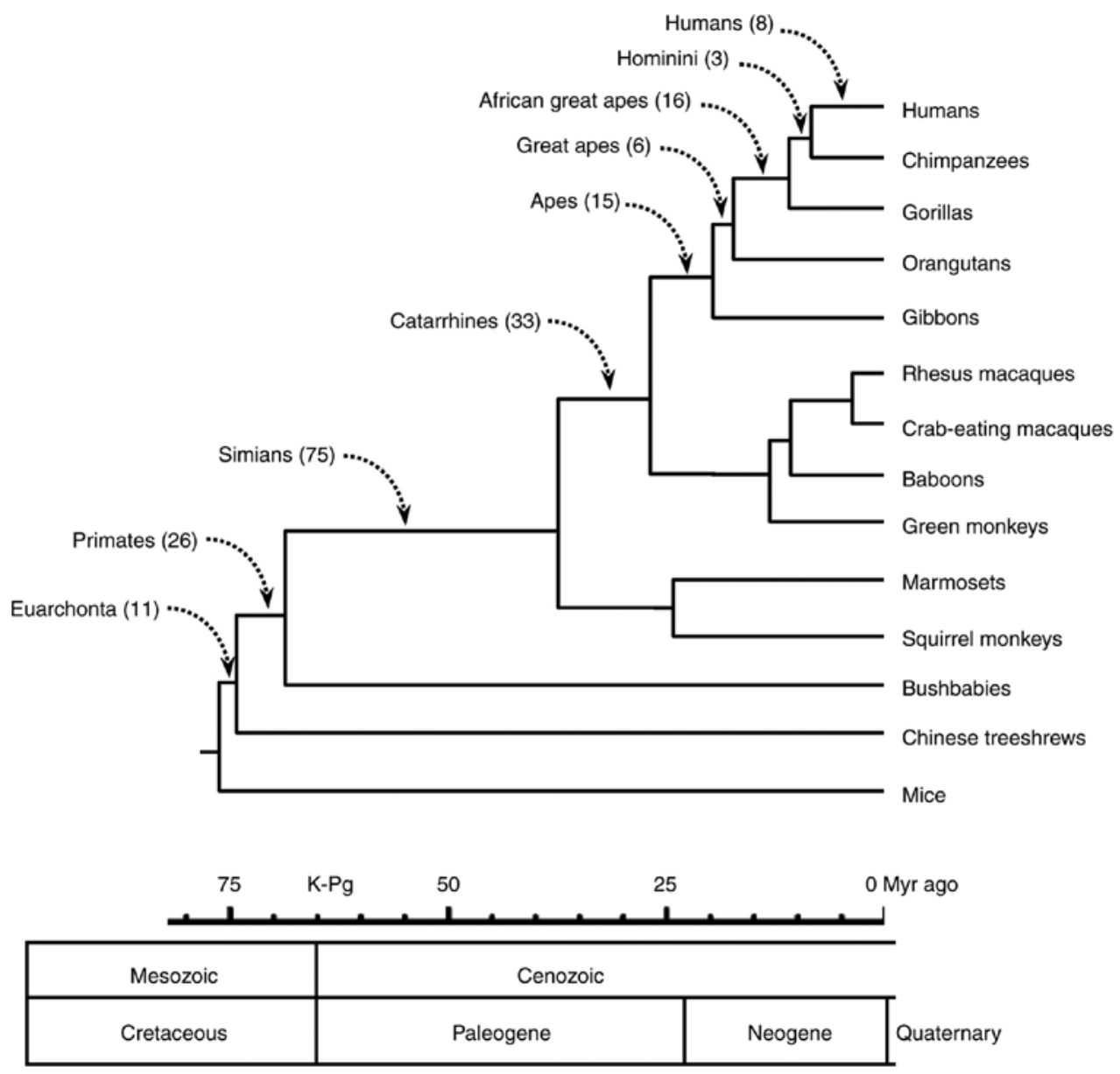

Figure 2. Timing of the loss of ubiquitylation sites in the lineage leading to humans. The number of lost ubiquitylation sites is indicated on the clade branches. Myr, million years; K-Pg, Cretaceous-Paleogene extinction event.

in mice (30). Therefore, if the modification at this lysine is conserved among mammals, the human BHMT protein would have lost 2 types of modifications concomitantly. The BHMT protein is a betaine-homocysteine $\mathrm{S}$-methyltransferase that converts homocysteine to methionine using betaine (trimethylglycine) and S-methylmethionine $(31,32)$. The enzyme has been demonstrated to be crucial for a wide range of biological processes, including inner cell mass development in embryogenesis (33) and normal brain development and function (34). At present, to the best of our knowledge, there have been no studies examining the molecular functions directly associated with this modifiable lysine in the mouse BHMT protein. However, due to the high level of sequence conservation of the lysine sequence in mammals and the 2 known alternative modifications in the mouse protein, it is highly likely that the loss of lysine in the human BHMT protein may be implicated in the acquisition of a novel phenotype in humans.

The human CNNM3 (NP_060093.3) protein specifically lost the lysine residue at aa position 491 (case no. 49), compared with its mouse counterpart, which possesses a lysine known to be a target for ubiquitylation (Fig. 3B). Instead, humans exhibit a threonine residue at this position, whereas the other 60 mammalian species have a conserved lysine residue. Pikas (O. princeps) are the only other species without this lysine as shown in Fig. 3B. CNNM3 is a member of a family of membrane-bound metal transporters that serve a critical role in magnesium homeostasis $(35,36)$. CNNM3 interacts with members of the protein tyrosine phosphatases $4 \mathrm{~A}$ family of proteins, also known as the phosphatase of regenerating liver family, namely PTP4A2 (PRL2) and PTP4A3 (PRL3), via its CBS domain $(36,37)$. This interaction has been implicated in the promotion of tumor formation and invasiveness in animals $(38,39)$. It would be valuable to investigate whether the loss of the conserved ubiquitylation site at aa position 491, which, according to the Pfam domain database, follows the CBS domain at 382-446, affects the interaction between the CNNM3 and PTP4A proteins.

During evolution, the human RRBP1 (NP_001036041.1) lost 3 lysine residues that are ubiquitylated in mice: The loss at aa position 936 (case no. 143) is human-specific, whereas those at the other 2 positions are shared with other primates (case nos. 141 and 142). With respect to aa position 936, humans have an arginine residue instead of a lysine (Fig. 3C). The lysine residue is conserved in all 56 mammalian species in which the RRBP1 protein sequence is present; the remaining 5 species did not contain an RRBP1 sequence, potentially due to the incompleteness of their genomic sequences. RRBP1 is a membrane-bound ribosome-binding protein identified on the rough endoplasmic reticulum (ER) (40) and is implicated in the regulation of the unfolded protein response (UPR) $(41,42)$. Overexpression of the RRBP1 protein has been demonstrated in numerous types of cancer and is correlated with the 


\begin{tabular}{|c|c|c|c|c|}
\hline \multirow{2}{*}{$\begin{array}{l}\text { A. BHMT } \\
\text { NP_001704.2 } 98 \\
03549098\end{array}$} & B. CNNM3 & C. RRBP1 & \multicolumn{2}{|c|}{ D. SLC37A4 } \\
\hline & $\begin{array}{l}\text { NP_060093.3 } 491 \\
\text { Q32NY4 497 }\end{array}$ & $\begin{array}{l}\text { NP_001036041.1936 } \\
\text { Q99PL5 } 1564\end{array}$ & $\begin{array}{l}\text { NP_001157751.1 } \\
\text { Q6WG34 } 205\end{array}$ & \\
\hline EKISGQEVNEAAC & DDEYKVT̈ISPQLL & LGRAATRLQELLK & LDPMPSEGKKGSL & hum Human \\
\hline$\ldots \ldots . . . . .$. & ............ & ............. & ....... & hom Chimp \\
\hline ............. & ............. & $\ldots \ldots k \ldots \ldots$ & ....... & aga Gorilla \\
\hline ............ & .....к...... & $\ldots \ldots \ldots \ldots$ & ......k. & gra Orangutan \\
\hline ............ & $\ldots \ldots \ldots$ к..... & $\ldots$ с..к...... & ...т..к. & ape Gibbon \\
\hline$\ldots \ldots \ldots, \ldots \ldots$ & $\ldots \ldots \ldots \ldots \ldots$ & $\ldots \ldots \ldots \ldots \ldots$ & ...т..к...... & cat Rhesus \\
\hline ............ & ........... & $\ldots \ldots \ldots \ldots \ldots$ & ...т.кк..... & cat Crab-eating macaque \\
\hline ............ & $\ldots \ldots \ldots$ к..... & $\ldots \ldots \ldots, \ldots \ldots$ & ...т.к...... & cat Baboon \\
\hline ............ & ............ & ............ & ...т.к...... & cat Green monkey \\
\hline ........... & ........... & $\ldots \ldots$ АК....... & ............. & sim Marmoset \\
\hline$\ldots \ldots \ldots \ldots \ldots$ & $\ldots \ldots \ldots$ к..... & $\ldots \ldots$ АК....... & ...ткк...... & sim Squirrel monkey \\
\hline ............ & .....к...... & $\ldots \ldots k \ldots . .$. & ...ТК.....А & pri Bushbaby \\
\hline$\ldots F \ldots k \ldots \ldots$ & $\ldots \ldots \ldots$ KL..... & $\ldots \mathrm{H} \ldots \mathrm{K} \ldots \ldots \mathrm{R}$ & ...Т.АК.....S & eua Chinese treeshrew \\
\hline$\ldots \ldots \ldots, \ldots \ldots$ & .E........... & $\ldots \ldots \ldots, \ldots \ldots$ & ...т.......s & gli Squirrel \\
\hline A............ & ............. & ..н...к....... & ...Т.......s & gli Lesser Egyptian jerboa \\
\hline ............ & ............ & $\ldots \ldots$ k...... & ...Т.....A.S & gli Prairie vole \\
\hline$\ldots \ldots \ldots$...... & $\ldots \ldots \ldots \ldots \ldots$ & $\ldots \ldots \ldots \ldots$ & ...T..K...D.S & gli Chinese hamster \\
\hline$\ldots \ldots \ldots$...... & $\ldots \ldots \ldots$ к...... & $\ldots \ldots \ldots$ к..... & ..LT..K.....S & gli Golden hamster \\
\hline$\ldots \ldots \ldots, \ldots \ldots$ & ............. & ......Iк....... & .....K.....S & gli Mouse \\
\hline ............ & ........... & ............. & ...A.......s & gli Rat \\
\hline .....EK....... & $. E \ldots \ldots . . . .$. & .....sk....... & ...т..к...... & gli Naked mole-rat \\
\hline ............ & .E.D.K....... & & ...т..к.....s & gli Guinea pig \\
\hline .....EK....... & .E........... & & ...т.к.....s & gli Chinchilla \\
\hline .....ЕК....... & .E........... & & ...т........s & gli Brush-tailed rat \\
\hline ..L...K...... & .............. & .............. & ...т..к.....s & gli Rabbit \\
\hline .....k....... & ...c.TR....... & $\ldots \ldots \ldots \ldots \ldots$ & ...т........s & gli Pika \\
\hline ............ & $\ldots \ldots . \overline{\mathrm{k}} \ldots \ldots$ & ............. & ...I.......s & lau Pig \\
\hline$\ldots \ldots \ldots \ldots$ &. $\mathrm{N} \ldots \ldots \mathrm{K} \ldots \ldots$ & $\ldots \ldots \ldots, \ldots \ldots$ & ... ......... & lau Alpaca \\
\hline$\ldots \ldots \ldots \ldots \ldots$ &.$N \ldots \ldots k \ldots \ldots$ & $\ldots \ldots \ldots \ldots$ & ...т.к....... & lau Bactrian camel \\
\hline$\ldots \ldots \ldots$...... & . D...к....... & .....к...... & ...т.к...... & lau Dolphin \\
\hline$\ldots \ldots \ldots$...... & .D...к....... & $\ldots \ldots \ldots$ к..... & ...т..к...... & lau Killer whale \\
\hline ............. & $\ldots \mathrm{DC} . . \mathrm{k} \ldots \ldots$ & ............. & ...т..к.....s & lau Tibetan antelope \\
\hline$\ldots \ldots \ldots, \ldots \ldots$ & $\ldots \mathrm{DC} . . \mathrm{K} \ldots \ldots$ & ............. & ...т......s & lau Cow \\
\hline$\ldots \ldots \ldots$ к...... & $\ldots \mathrm{DC} . \mathrm{K} \ldots \ldots$ & ............. & ...т.......s & lau Sheep \\
\hline ............. & $\ldots \mathrm{DC} . \mathrm{K} \ldots \ldots$ & $\ldots \ldots \ldots$ к...... & ...І.к.....s & lau Domestic goat \\
\hline$\ldots \ldots$ кк...... & .ED...K....... & $\ldots \ldots \ldots \ldots \ldots$ & ...т..к...... & lau Horse \\
\hline$. м . \ldots k \ldots \ldots$ & .DC.AK....... & $\ldots \ldots \ldots \ldots . . .$. & ...т.......s & lau White rhinoceros \\
\hline$\ldots \ldots \ldots$...... & $\ldots \ldots \ldots \ldots$ & $\ldots \ldots \ldots \ldots \ldots$ & $\ldots$...KD....S & lau Cat \\
\hline ............ & $\ldots \ldots \ldots \ldots \ldots$ & ..н...к....... & ...т..к...... & lau Dog \\
\hline ............ & $\ldots \ldots \ldots \ldots$ & $\ldots \ldots k \ldots . .$. & $\ldots$...к.....s & lau Ferret \\
\hline ........... & ........... & $\ldots c \ldots k \ldots . .$. & .....к...... & lau Panda \\
\hline$\ldots$ т..к...... & ..ннкк....... & ............. & $\ldots$ Т.АК....... & lau pacific walrus \\
\hline ............ & ..н.кк..... & $\ldots \ldots k \ldots . .$. & $\ldots$ Т.АК $\ldots . .$. & lau Weddell seal \\
\hline$\ldots \ldots \ldots, \ldots \ldots$ & GEGC..K...... & $\ldots \ldots \ldots, \ldots \ldots$ & $\ldots$.SP..N...... & lau Black flying-fox \\
\hline ............. & GEGC..K...... & ............. & ..SP..N...... & lau Megabat \\
\hline$\ldots \ldots \ldots$...... &.$N \ldots \ldots k \ldots \ldots$ & ............. & ...T.AK....AM & lau David's myotis bat \\
\hline$\ldots \ldots \ldots$ к..... &.$N \ldots \ldots k \ldots \ldots$ & ............. & ...т.к.....м & lau Microbat \\
\hline$\ldots \ldots \ldots$...... & .....к...... & ............. & ..т..к.....v & lau Big brown bat \\
\hline ............. & .N.C..K...... & $\ldots \ldots \ldots \ldots$ & ...........A & lau Hedgehog \\
\hline$\ldots \ldots \ldots \ldots$ & E.DC..K...... & & ..Т..К..Р..Р & lau Shrew \\
\hline$\ldots \ldots \ldots$....... & .D...k....... & $\ldots \ldots \ldots, \ldots \ldots$ & ...т..к...... & lau Star-nosed mole \\
\hline ............ & ............. & $\ldots \ldots \ldots, \ldots \ldots$ & ...т..к.....м & afr Elephant \\
\hline$\ldots \ldots \ldots$ к...... & E..C..K...... & $\ldots \ldots \ldots$ к..... & ..Т.АК.....P & afr Cape elephant shrew \\
\hline$\ldots \ldots \ldots$ к...... & ..DS......... & $\ldots Q \ldots \kappa \ldots \ldots$ & V..T..KR....V & afr Manatee \\
\hline$\ldots \ldots$ LK...... & $\ldots \ldots \ldots \ldots \ldots$ & .....sk....... & ..т..к...... & afr Cape golden mole \\
\hline ............. & .EAF..K...... & $\ldots \ldots \ldots$...... & ...т.тк....... & afr Tenrec \\
\hline$\ldots \ldots \ldots, \ldots \ldots$ & $\ldots \ldots \ldots$ к..... & .A........... & ...т..к...... & afr Aardvark \\
\hline$\ldots \ldots \ldots$...... & .s.c..k...... & ............. & ... .к....... & afr Armadillo \\
\hline$\ldots \ldots \ldots$ к...... & $. N . \ldots k \ldots \ldots$ & ............ & І..Т.КK.....Q & mar Opossum \\
\hline$\ldots \ldots \ldots \ldots$ &.$N \ldots \ldots k \ldots$ & & ...Т.кК.....Q & mar Tasmanian devil \\
\hline ....WKG. . . &.$N \ldots \ldots k \ldots \ldots$ & ..Q.TAK..G... & ...Т.кк.....Q & mar Wallaby \\
\hline Q......... & EG.N..K...... & ............. & & mar Platypus \\
\hline
\end{tabular}

Figure 3. Examples of human-specific loss of ubiquitylation sites. The ancestral ubiquitylation sites and the surrounding regions of (A) BHMT, (B) CNNM3, (C) RRBP1 and (D) SLC37A4 are indicated. Lysine and non-lysine residues are marked by a gray and black background, respectively. Note that certain sequences are missing due to incomplete sequencing or low-quality sequence data. K, lysine; BHMT, betaine homocysteine S-methyltransferase; CNNM3, metal transporter CNNM3; RRBP1, ribosome-binding protein 1; SLC37A4, solute carrier family 37 member 4.

progression and survival of these types of cancer (41,43-45). A molecular functional study focusing on the loss of this ubiquitylation site in human RRBP1 may provide a means of identifying potential human-specific traits associated with the UPR and tumorigenesis.
During evolution, following the human-chimpanzee divergence, the human protein SLC37A4 (NP_001157751.1) lost a ubiquitylation site at aa position 132 (case no. 159; (Fig. 3D). At this position, humans have a glutamic acid, whereas 58 other mammals have a conserved lysine. Black 
Table II. Other modifications at the mouse ubiquitylated lysine residues that were lost during human evolution.

\begin{tabular}{lllrllrl}
\hline $\begin{array}{l}\text { Case } \\
\text { no. }\end{array}$ & Gene & Human RefSeq & $\begin{array}{r}\text { Human } \\
\text { position }\end{array}$ & \multicolumn{1}{c}{ Clade } & $\begin{array}{c}\text { Mouse } \\
\text { UniProt }\end{array}$ & $\begin{array}{c}\text { Mouse } \\
\text { position }\end{array}$ & \multicolumn{1}{c}{ Modification } \\
\hline 7 & ACADM & NP_001120800.1 & 83 & Simians & P45952 & 79 & Acetylation \\
8 & ACAT1 & NP_000010.1 & 245 & Catarrhines & Q8QZT1 & 242 & Acetylation, Succinylation \\
12 & ACO2 & NP_001089.1 & 517 & Catarrhines & Q99KI0 & 517 & Acetylation, Succinylation \\
23 & ALDH2 & NP_000681.2 & 441 & Simians & P47738 & 443 & Acetylation \\
31 & ATP5J & NP_001003696.1 & 84 & Great apes & P97450 & 84 & Acetylation, Succinylation \\
33 & BAAT & NP_001692.1 & 40 & Catarrhines & Q91X34 & 40 & Succinylation \\
34 & BHMT & NP_001704.2 & 98 & Humans & O35490 & 98 & Succinylation \\
40 & CAT & NP_001743.1 & 13 & African great apes & P24270 & 13 & Succinylation \\
51 & CPS1 & NP_001866.2 & 603 & Primates & Q8C196 & 603 & Acetylation, Succinylation \\
53 & CYB5R3 & NP_001123291.1 & 27 & Simians & Q9DCN2 & 50 & Acetylation \\
63 & EHHADH & NP_001957.2 & 331 & Euarchonta & Q9DBM2 & 329 & Succinylation \\
65 & ENO3 & NP_443739.3 & 71 & African great apes & P21550 & 71 & Acetylation \\
68 & EPHX2 & NP_001970.2 & 505 & Humans & P34914 & 504 & Succinylation \\
77 & GLYCTK & NP_660305.2 & 200 & Catarrhines & Q8QZY2 & 200 & Acetylation \\
82 & GOT1 & NP_002070.1 & 318 & Catarrhines & P05201 & 318 & Succinylation \\
86 & HADHA & NP_000173.2 & 620 & Simians & Q8BMS1 & 620 & Succinylation \\
147 & SCP2 & NP_002970.2 & 40 & Simians & P32020 & 40 & Succinylation \\
\hline
\end{tabular}

flying foxes ( $P$. alecto) and megabats (P. vampyrus) have also independently lost this lysine and have an arginine residue instead. SLC37A4 is the glucose 6-phosphate transporter localized in the ER membrane, and is responsible for transporting glucose-6-phosphate from the cytoplasm into the ER lumen (46). SLC37A4 serves a key role in the maintenance of blood glucose homeostasis, and its inactivation causes glycogen storage disease types Ib and Ic $(47,48)$. It has also been identified as being a key regulator in the initiation step for autophagy (49). It would be valuable to explore if the loss of this conserved ubiquitylation site in the human SLC37A4 protein is involved with the emergence of a novel human-specific trait associated with glucose homeostasis.

Certain lost ubiquitylated lysines are target sites for other PTMs. Lysine residues are target sites for other PTMs, including acetylation, methylation, succinylation and malonylation (50). Therefore, the loss of a lysine residue may affect regulation not only by ubiquitylation, but also by other modifications. To determine whether the ubiquitylation sites lost in human proteins were potential targets for other modifications, the mouse sequences in the UniProt database were additionally examined. This analysis revealed that 17 ubiquitylated lysines were identified to be also modified by acetylation or succinylation in mice (Table II): 4 sites were modified by either acetylation or succinylation; 5 sites by acetylation alone; and 8 sites by succinylation alone.

Although it must be confirmed experimentally, it is highly likely that the same PTMs may occur in other species, as the lysine residues are highly conserved. Therefore, these lysines may be target sites for multiple alternative PTMs, which may be involved in refining the molecular functions of the target proteins so that they modulate a wide range of biological processes. Loss of these multiple modification sites may result in rewiring of the associated protein regulatory networks.

Of the 17 sites identified as being targets for multiple PTMs, 2 sites were lost in the human protein [BHMT (case no. 34) and EPHX2 (case no. 68)] following the divergence of humans and chimpanzees. These are the human BMHT protein aa position 98 (NP_001704.2, case no. 34) and the EPHX2 protein aa position 505 (NP_001970.2, case no. 68). The corresponding positions in the mouse proteins were demonstrated to be subject to succinylation (30). Molecular functional studies of these 2 cases may reveal instances of rearrangement of the protein regulatory networks during human evolution.

Certain lost ubiquitylation sites may be compensated for by novel sites. A previous study indicated that ubiquitylation sites may move from their original position to a nearby lysine that appears during the evolutionary process (51). This means that the existence of a ubiquitylation site within a segment, rather than the exact position, is important for the regulation of protein function. Therefore, a modification site may move around over time, within a small window of the peptide sequence. This phenomenon has been commonly identified to occur for sites modified by phosphorylation (52). A previous study on the gain of novel ubiquitylation sites during human evolution have indicated that certain conserved lysines disappeared and novel ubiquitylated sites appeared along the human lineage, suggesting that the ubiquitylation site may have shifted during human evolution (24).

To assess if a potential turnover event occurred along with the loss of a ubiquitylation site, a 13-aa window with the lost site at the center was used in the present study. When a novel lysine residue appeared at a nearby flanking site, it was considered a turnover event. There were 8 such cases, in which a novel lysine was identified in the human protein at a site up 
to 6 residues away from the lost site: These were case nos. 83, $85,98,100,119,138,147$ and 162 .

In 3 cases (nos. 83, 100 and 119), the gain of the novel lysine coincided with the loss of the ancestral lysine, markedly implying a turnover of the ubiquitylation site. The $\mathrm{G}$-protein coupled receptor 39 protein lost an ancestral lysine at the position corresponding to the human protein aa position 253 (NP_001499.1) in catarrhines, but a novel lysine appeared at the next position ( +1 position) in the same clade (case no. 83). At aa position 146 (NP_005359.1) in the human MB protein, a lysine disappeared in apes, but a novel lysine appeared at the -5 position concomitantly (case no. 100). The human nitric oxide synthase, brain protein lacked a lysine at aa position 221 (NP_001191147.1) that was lost in simians, but a novel lysine was present at the +3 position in all simians (case no. 119). The coincidence of the loss and gain of lysines in these cases suggests that the novel lysine may compensate for the lost one.

In two cases (nos. 138 and 162), the gain of a novel lysine residue preceded the loss of the ancestral lysine. The ape regulator of microtubule dynamics protein 2 proteins lacked an ancestral lysine at the position corresponding to aa position 41 in the human protein (NP_001164263.1), but a novel lysine at the -3 position appeared in the ancestral catarrhine, which preceded this loss (case no. 138). At aa position 495 in the human sodium/glucose cotransporter 1 protein (NP_001243243.1), the ancestral lysine was lost in catarrhines, but a new lysine at +4 position was present in all simians (case no. 162). Therefore, it is possible that these proteins gained a novel ubiquitylation site that replaced the function of the ancestral site and was subsequently lost.

In the remaining 3 cases (nos. 85, 98, and 147), the emergence of the novel lysine appeared to occur much later, following the loss of the ancestral lysine. For example, the primate 3-hydroxyanthranilate 3,4-dioxygenase protein lacked an ancestral lysine at the position corresponding to aa position 8 in the human protein (NP_036337.2), but humans exhibited a novel lysine residue at the +4 position (case no. 85). Concurrently, in the catarrhine ancestor, the plastin-2 protein lost a lysine at the position corresponding to aa position 530 in the human protein (NP_002289.2), but humans gained a novel lysine at the +3 position (case no. 98 ). As these 2 sites in these human proteins were not shared with other primates, these events cannot be considered as a timely turnover event. However, it is possible that humans restored a ubiquitylation site in the corresponding segments of these proteins. In the case of the non-specific lipid-transfer protein, the ancestral lysine at the position corresponding to aa position 40 in the human protein (NP_002970.2) was absent in simians, but a novel lysine was present in apes at the +4 position (case no. 147).

Loss of ubiquitylation sites may lead to the development of novel phenotypes. The gain or loss of PTM sites in proteins may lead to changes in the activity of a protein and may contribute to the development to a novel phenotype $(53,54)$. In this regard, certain novel ubiquitylation sites that have evolved during human evolution have been suggested to be associated with the development of novel beneficial traits (24). For example, a novel ubiquitylation site in the human general transcription and DNA repair factor IIH helicase subunit XPD protein is associated with enhanced DNA repair activity in humans, which may have developed to provide extra protection for skin cells from ultraviolet light-induced DNA damages when ancestral humans lost their body hair and started to live in open plains (55).

Ubiquitylation serves crucial roles in numerous biological processes, including innate and adaptive immune responses, by regulating pattern-recognition receptor signaling and activating dendritic cells (56-58). Mutations of ubiquitin ligases and disruption of ubiquitylation modifications of proteins have frequently been observed in immune disorders, cancer, and neurodegenerative diseases including Parkinson's disease and Huntington's disease (7,59-62). There are numerous previous studies indicating that natural or experimental mutations of lysines within PTMs may disrupt normal protein function, which results in disease phenotypes (63-67). However, the present study demonstrated that the 8 ubiquitylation sites that were lost during human evolution were completely or almost fixed in modern humans, and the remaining 185 cases were shared in humans and other primates, implying that these losses do not confer a disease phenotype in extant primates. The loss of a ubiquitylation site may be compensated for by other genetic changes or be selected for when it increases the fitness of the species.

Therefore, the loss of a ubiquitylation site during organismal evolution may lead to the emergence of an advantageous phenotype and may be fixed by selection. Molecular functional studies of the conserved mammalian ubiquitylation sites that are lost in human proteins may reveal potential beneficial phenotypes associated with the loss. The ancestral ubiquitylation sites identified in the present study may serve as a good resource for investigating the association between the loss of ubiquitylation sites and the emergence of novel phenotypes during the evolution towards modern humans.

\section{Acknowledgements}

Not applicable.

\section{Funding}

The present study was supported by the National Research Foundation of Korea funded by the Government of Korea (grant no., 2017R1A1B4005866).

\section{Availability of data and materials}

The datasets used and/or analyzed in the present study are available from the corresponding author on reasonable request. The complete list and detailed sequence alignments of the 193 lost ubiquitylation sites identified in the present study are available through the Figshare repository (https://figshare. com/s/2f6d03011988cf071a1c and https://figshare.com/s/af4abd53ed0a9bad36f2, respectively).

\section{Authors' contributions}

YH conceived and designed the experiments; DP, CJG, HK, JSL and YH analyzed data. YH wrote the paper. 


\section{Ethics approval and consent to participate}

Not applicable.

\section{Patient consent for publication}

Not applicable.

\section{Competing interests}

The authors declare that they have no competing interests.

\section{References}

1. Kerscher O, Felberbaum R and Hochstrasser M: Modification of proteins by ubiquitin and ubiquitin-like proteins. Annu Rev Cell Dev Biol 22: 159-180, 2006.

2. Komander D and Rape M: The ubiquitin code. Annu Rev Biochem 81: 203-229, 2012.

3. Swatek KN and Komander D: Ubiquitin modifications. Cell Res 26: 399-422, 2016.

4. Kwon YT and Ciechanover A: The ubiquitin code in the ubiquitin-proteasome system and autophagy. Trends Biochem Sci 42 873-886, 2017.

5. Konstantinova IM, Tsimokha AS and Mittenberg AG: Role of proteasomes in cellular regulation. Int Rev Cell Mol Biol 267: 59-124, 2008.

6. Preston GM and Brodsky JL: The evolving role of ubiquitin modification in endoplasmic reticulum-associated degradation. Biochem J 474: 445-469, 2017.

7. Popovic D, Vucic D and Dikic I: Ubiquitination in disease pathogenesis and treatment. Nat Med 20: 1242-1253, 2014.

8. Stojkovic K, Wing SS and Cermakian N: A central role for ubiquitination within a circadian clock protein modification code. Front Mol Neurosci 7: 69, 2014.

9. Kim W, Bennett EJ, Huttlin EL, Guo A, Li J, Possemato A, Sowa ME, Rad R, Rush J, Comb MJ, et al: Systematic and quantitative assessment of the ubiquitin-modified proteome. Mol Cell 44: 325-340, 2011.

10. Wagner SA, Beli P, Weinert BT, Nielsen ML, Cox J, Mann M and Choudhary C: A proteome-wide, quantitative survey of in vivo ubiquitylation sites reveals widespread regulatory roles. Mol Cell Proteomics 10: M111 013284, 2011.

11. Caron C, Boyault $\mathrm{C}$ and Khochbin S: Regulatory cross-talk between lysine acetylation and ubiquitination: Role in the control of protein stability. BioEssays 27: 408-415, 2005.

12. Hunter T: The age of crosstalk: Phosphorylation, ubiquitination, and beyond. Mol Cell 28: 730-738, 2007.

13. Chen ZJ: Ubiquitin signalling in the NF-kappaB pathway. Nat Cell Biol 7: 758-765, 2005.

14. Al-Hakim AK, Zagorska A, Chapman L, Deak M, Peggie M and Alessi DR: Control of AMPK-related kinases by USP9X and atypical Lys(29)/Lys(33)-linked polyubiquitin chains. Biochem J 411: 249-260, 2008.

15. Li WH and Saunders MA: News and views: The chimpanzee and us. Nature 437: 50-51, 2005.

16. Varki A and Altheide TK: Comparing the human and chimpanzee genomes: Searching for needles in a haystack. Genome Res 15: 1746-1758, 2005.

17. Ruiz-Orera J, Hernandez-Rodriguez J, Chiva C, Sabidó E, Kondova I, Bontrop R, Marqués-Bonet T and Albà MM: Origins of de novo genes in human and chimpanzee. PLoS Genet 11 e1005721, 2015

18. Kim DS and Hahn Y: Identification of human-specific transcript variants induced by DNA insertions in the human genome. Bioinformatics 27: 14-21, 2011.

19. Hahn Y, Jeong S and Lee B: Inactivation of MOXD2 and S100A15A by exon deletion during human evolution. Mol Biol Evol 24: 2203-2212, 2007.

20. Zhu J, Sanborn JZ, Diekhans M, Lowe CB, Pringle TH and Haussler D: Comparative genomics search for losses of long-established genes on the human lineage. PLoS Comput Biol 3: e247, 2007.

21. Oh HJ, Choi D, Goh CJ and Hahn Y: Loss of gene function and evolution of human phenotypes. BMB Rep 48: 373-379, 2015.
22. Lynch VJ, May G and Wagner GP: Regulatory evolution through divergence of a phosphoswitch in the transcription factor CEBPB. Nature 480: 383-386, 2011.

23. Kim DS and Hahn Y: Identification of novel phosphorylation modification sites in human proteins that originated after the human-chimpanzee divergence. Bioinformatics 27: 2494-2501, 2011.

24. Kim DS and Hahn Y: Gains of ubiquitylation sites in highly conserved proteins in the human lineage. BMC Bioinformatics 13 306, 2012.

25. Kim DS and Hahn Y: The acquisition of novel N-glycosylation sites in conserved proteins during human evolution. BMC Bioinformatics 16: 29, 2015

26. Kim DS, Choi D and Hahn Y: Loss of ancestral N-glycosylation sites in conserved proteins during human evolution. Int $\mathrm{J}$ Mol Med 36: 1685-1692, 2015.

27. Chen T, Zhou T, He B, Yu H, Guo X, Song X and Sha J: mUbiSiDa: A comprehensive database for protein ubiquitination sites in mammals. PLoS One 9: e85744, 2014.

28. Rosenbloom KR, Armstrong J, Barber GP, Casper J, Clawson H, Diekhans M, Dreszer TR, Fujita PA, Guruvadoo L, Haeussler M, et al: The UCSC genome browser database: 2015 update. Nucleic Acids Res 43: D670-D681, 2015.

29. Blanchette M, Kent WJ, Riemer C, Elnitski L, Smit AF, Roskin KM, Baertsch R, Rosenbloom K, Clawson H, Green ED, et al: Aligning multiple genomic sequences with the threaded blockset aligner. Genome Res 14: 708-715, 2004.

30. Park J, Chen Y, Tishkoff DX, Peng C, Tan M, Dai L, Xie Z, Zhang Y, Zwaans BM, Skinner ME, et al: SIRT5-mediated lysine desuccinylation impacts diverse metabolic pathways. Mol Cell 50: 919-930, 2013.

31. Finkelstein JD, Harris BJ and Kyle WE: Methionine metabolism in mammals: Kinetic study of betaine-homocysteine methyltransferase. Arch Biochem Biophys 153: 320-324, 1972.

32. Garrow TA: Purification, kinetic properties, and cDNA cloning of mammalian betaine-homocysteine methyltransferase. J Biol Chem 271: 22831-22838, 1996.

33. Lee MB, Kooistra M, Zhang B, Slow S, Fortier AL, Garrow TA, Lever M, Trasler JM and Baltz JM: Betaine homocysteine methyltransferase is active in the mouse blastocyst and promotes inner cell mass development. J Biol Chem 287: 33094-33103, 2012.

34. Prieur EAK, Pjetri E, Zeisel SH and Jadavji NM: Reduced brain volume and impaired memory in betaine homocysteine S-methyltransferase knockout mice. Appl Physiol Nutr Metab 42: 1228-1231, 2017

35. Islam Z, Hayashi N, Inoue H, Umezawa T, Kimura Y, Doi H, Romero MF, Hirose S and Kato A: Identification and lateral membrane localization of cyclin M3, likely to be involved in renal $\mathrm{Mg}^{2+}$ handling in seawater fish. Am J Physiol Regul Integr Comp Physiol 307: R525-R537, 2014.

36. Gulerez I, Funato Y, Wu H, Yang M, Kozlov G, Miki H and Gehring K: Phosphocysteine in the PRL-CNNM pathway mediates magnesium homeostasis. EMBO Rep 17: 1890-1900, 2016.

37. Zhang H, Kozlov G, Li X, Wu H, Gulerez I and Gehring K: PRL3 phosphatase active site is required for binding the putative magnesium transporter CNNM3. Sci Rep 7: 48, 2017.

38. Hardy S, Uetani N, Wong N, Kostantin E, Labbé DP, Bégin LR, Mes-Masson A, Miranda-Saavedra D and Tremblay ML: The protein tyrosine phosphatase PRL-2 interacts with the magnesium transporter CNNM3 to promote oncogenesis. Oncogene 34 : 986-995, 2015

39. Kostantin E, Hardy S, Valinsky WC, Kompatscher A, de Baaij JH, Zolotarov Y, Landry M, Uetani N, Martínez-Cruz LA, Hoenderop JG, et al: Inhibition of PRL-2-CNNM3 protein complex formation decreases breast cancer proliferation and tumor growth. J Biol Chem 291: 10716-10725, 2016.

40. Savitz AJ and Meyer DI: Identification of a ribosome receptor in the rough endoplasmic reticulum. Nature 346: 540-544, 1990.

41. Tsai HY, Yang YF, Wu AT, Yang CJ, Liu YP, Jan YH, Lee CH, Hsiao YW, Yeh CT, Shen CN, et al: Endoplasmic reticulum ribosome-binding protein 1 (RRBP1) overexpression is frequently found in lung cancer patients and alleviates intracellular stress-induced apoptosis through the enhancement of GRP78. Oncogene 32: 4921-4931, 2013.

42. Hyde M, Block-Alper L, Felix J, Webster P and Meyer DI: Induction of secretory pathway components in yeast is associated with increased stability of their mRNA. J Cell Biol 156: 993-1001, 2002. 
43. Telikicherla D, Marimuthu A, Kashyap MK, Ramachandra YL, Mohan S, Roa JC, Maharudraiah J and Pandey A: Overexpression of ribosome binding protein 1 (RRBP1) in breast cancer. Clin Proteomics 9: 7, 2012.

44. Liang X, Sun S, Zhang X, Wu H, Tao W, Liu T, Wei W, Geng J and Pang D: Expression of ribosome-binding protein 1 correlates with shorter survival in Her-2 positive breast cancer. Cancer Sci 106: 740-746, 2015.

45. Pan Y, Cao F, Guo A, Chang W, Chen X, Ma W, Gao X, Guo S, $\mathrm{Fu} \mathrm{C}$ and Zhu J: Endoplasmic reticulum ribosome-binding protein 1, RRBP1, promotes progression of colorectal cancer and predicts an unfavourable prognosis. Br J Cancer 113: 763-772, 2015.

46. Gerin I, Veiga-da-Cunha M, Achouri Y, Collet JF and Van Schaftingen E: Sequence of a putative glucose 6-phosphate translocase, mutated in glycogen storage disease type Ib. FEBS Lett 419: 235-238, 1997.

47. Veiga-da-Cunha M, Gerin I, Chen YT, de Barsy T, de Lonlay P, Dionisi-Vici C, Fenske CD, Lee PJ, Leonard JV, Maire I, et al: A gene on chromosome 11q23 coding for a putative glucose6-phosphate translocase is mutated in glycogen-storage disease types Ib and Ic. Am J Hum Genet 63: 976-983, 1998.

48. Chou JY and Mansfield BC: The SLC37 family of sugar-phosphate/phosphate exchangers. Curr Top Membr 73: 357-382, 2014.

49. Ahn HH, Oh Y, Lee H, Lee W, Chang JW, Pyo HK, Nah do H and Jung YK: Identification of glucose-6-phosphate transporter as a key regulator functioning at the autophagy initiation step. FEBS Lett 589: 2100-2109, 2015.

50. Azevedo $C$ and Saiardi A: Why always lysine? The ongoing tale of one of the most modified amino acids. Adv Biol Regul 60: $144-150,2016$

51. Hagai T, Toth-Petroczy A, Azia A and Levy Y: The origins and evolution of ubiquitination sites. Mol Biosyst 8: 1865-1877, 2012.

52. Moses AM, Liku ME, Li JJ and Durbin R: Regulatory evolution in proteins by turnover and lineage-specific changes of cyclin-dependent kinase consensus sites. Proc Natl Acad Sci USA 104: 17713-17718, 2007.

53. Gulzar N, Dingerdissen H, Yan C and Mazumder R: Impact of nonsynonymous single-nucleotide variations on post-translational modification sites in human proteins. Methods Mol Biol 1558: 159-190, 2017.

54. Lu L, Li Y, Liu Z, Liang F, Guo F, Yang S, Wang D, He Y, Xiong J, Li D and He F: Functional constraints on adaptive evolution of protein ubiquitination sites. Sci Rep 7: 39949, 2017.
55. Lehmann AR: DNA repair-deficient diseases, xeroderma pigmentosum, Cockayne syndrome and trichothiodystrophy. Biochimie 85: 1101-1111, 2003.

56. $\mathrm{Hu} \mathrm{H}$ and Sun SC: Ubiquitin signaling in immune responses. Cell Res 26: 457-483, 2016

57. Zohaib A, Duan X, Zhu B, Ye J, Wan S, Chen H, Liu X and Cao $S$ : The role of ubiquitination in regulation of innate immune signaling. Curr Issues Mol Biol 18: 1-10, 2016.

58. Liu X, Wang Q, Chen $\mathrm{W}$ and Wang C: Dynamic regulation of innate immunity by ubiquitin and ubiquitin-like proteins. Cytokine Growth Factor Rev 24: 559-570, 2013.

59. Chakraborty J, Basso V and Ziviani E: Post translational modification of Parkin. Biol Direct 12: 6, 2017.

60. Fulda S, Rajalingam K and Dikic I: Ubiquitylation in immune disorders and cancer: From molecular mechanisms to therapeutic implications. EMBO Mol Med 4: 545-556, 2012.

61. Narayan S, Bader GD and Reimand J: Frequent mutations in acetylation and ubiquitination sites suggest novel driver mechanisms of cancer. Genome Med 8: 55, 2016.

62. Ortega $Z$ and Lucas JJ: Ubiquitin-proteasome system involvement in Huntington's disease. Front Mol Neurosci 7: 77, 2014

63. McClurg UL, Cork DMW, Darby S, Ryan-Munden CA, Nakjang S, Mendes Côrtes L, Treumann A, Gaughan L and Robson CN: Identification of a novel K311 ubiquitination site critical for androgen receptor transcriptional activity. Nucleic Acids Res 45: 1793-1804, 2017.

64. Bonacci T, Audebert S, Camoin L, Baudelet E, Iovanna JL and Soubeyran P: Regulation of NUB1 activity through non-proteolytic Mdm2-mediated ubiquitination. PLoS One 12: e0169988, 2017.

65. Glorian V, Allègre J, Berthelet J, Dumetier B, Boutanquoi PM, Droin N, Kayaci C, Cartier J, Gemble S, Marcion G, et al: DNA damage and S phase-dependent E2F1 stabilization requires the cIAP1 E3-ubiquitin ligase and is associated with K63-poly-ubiquitination on lysine 161/164 residues. Cell Death Dis 8: e2816, 2017.

66. Tessadori F, Giltay JC, Hurst JA, Massink MP, Duran K, Vos HR, van Es RM; Deciphering Developmental Disorders Study, Scott RH, van Gassen KLI, et al: Germline mutations affecting the histone $\mathrm{H} 4$ core cause a developmental syndrome by altering DNA damage response and cell cycle control. Nat Genet 49: 1642-1646, 2017

67. Kim OJ: A single mutation at lysine 241 alters expression and trafficking of the D2 dopamine receptor. J Recept Signal Transduct Res 28: 453-464, 2008. 